\title{
3 Changing Attitudes to Disability
}

\section{The shift from charity thinking to social and human rights thinking}

For thousands of years in every culture and society physical and mental differences have been ascribed special meaning. This was usually negative and often persists today, resulting in stigma, negative attitudes and stereotypes.

People were thought to be disabled because they or their parents had done something wrong and because all-powerful gods, deities or fate had made them disabled (karma or sin). Disabled people were often subjected to inhuman treatment. Being seen as bringing shame on their families, they were locked away. Euthanasia was widely practised on babies born with significant impairments. Such children were often abandoned and had to rely on begging to survive..$^{53}$

It was believed that disabled people brought bad luck because they had been cursed or had a spell placed upon them by witchcraft. They were often viewed as not fully human or possessed by evil spirits. This made it easy to make fun of or ridicule them. They became the butt of jokes and symbols for all the ills of the world. Clowns, court jesters and 'freak shows' are illustrations of this. Quarmby (2011) has provided an in-depth analysis of negative attitudes to disability in the West. She has linked them in a detailed way with scapegoating and hate crime towards disabled people in the UK. Unfortunately, disabled people are regularly subjected to hate and violence, drawing on this cultural residue.

There are many cultural and literary manifestations of this thinking which are still being reinforced in myths, legend or literature. Even modern films, comics and television programmes draw upon and reinforce these negative stereotypes. Stereotypes are bundles of negative and untrue perceptions which often condition how people treat and respond to disabled people. ${ }^{54}$ Similar activity is on the increase in central and east Africa with as many as 6,000 people with albinism killed for the supposed magical properties of their limbs in the last few years. ${ }^{55}$

The elements of traditional model thinking in southern Africa ${ }^{56}$ listed in Box 3.1 were identified by 32 participants in a 2007 workshop attended by disabled people, parents of disabled children and government officials from Botswana, Lesotho, Malawi, Mozambique, Namibia, Swaziland, Zambia and Zimbabwe. They demonstrate clearly the power of the traditional model of disability in Africa as a barrier to inclusion. In 2011 World of Inclusion Ltd carried out a six-day UNCRPD capacity building workshop in Port Moresby for the UK Disabled People's Council and the Commonwealth Foundation. Disabled leaders and disabled young leaders from Kiribati, Nauru, Papua New Guinea, Samoa, Solomon Islands, Tonga, Tuvalu and Vanuatu took part and came up with a wide range of traditional ideas about disability that are still very much part of people's thinking on the ground (Box 3.2). Such ideas need uncovering and discussing, and alternative views must be introduced based on human rights.

Box 3.1 Commonly held views about disabled people in Southern Africa

Demon possessed

Bewitched/a curse

A moron/idiot/stupid
Tools to scare children

Tools for begging

Expressing bad feelings 
Non-achievers

Disability is contagious

Less of a human being

Disability is a result of incest

Sick people

Government has other priorities than spending/wasting money on disability Useless to society

Naughty

Disgusting to family members

Shameful

Punishment from God for evil deeds

Albinos do not die, but they disappear Mother blamed for having a disabled child - has been unfaithful to husband People with disabilities are God's people - known as beggars

They are AIDS carriers

Objects of pity

Asexual - have no sexual feeling

Mothers are always blamed for bearing disabled children and are therefore abandoned
Sign of misfortune

Rude people

Short-tempered people

Invalids

Mad people

You have a child with a disability

as a punishment

They are not worth it

They are a problem

They are a burden

They are argumentative

They cannot think on their own

They are unproductive

While pregnant the mother laughed

at a traditional Gulewankulu dancer

They remain children - they are not expected to behave like adults

They cannot be educated

They cannot have children

They will have disabled children

They do not have sex - HIV carriers

It is believed that having sex with a disabled person is a cure for the HIV virus

Box 3.2 Traditional views of disabled people in the South Pacific

These include:

- Mental impairment is caused by sorcerers/curses

- Slow development of children - uncaring parents during pregnancy or child's development

- Physical impairment is the person's own fault

- If they are born with a physical impairment this is because either the parents separated or there is a scandal in the family

- Disability is the fault of a sinful mother

- Breaking the taboo, e.g. sleeping/doing something in a taboo place (taboo $=$ restricted areas)

- If pregnant mothers eat reptiles like eel-fish cats or flying foxes, their child will become disabled

- Bride price and disability: If the bride price is used to buy food, the profit becomes a cause of disability

- Wrong marriages causes disability

- Uncivilised (rape people with disabilities) 
- Cultures sometimes teach that people with disabilities are possessors of evil or ancestral spirits

- Disabled people are bad, leave our families in isolation

- Laughing, teasing, labelling, discrimination, distance, body language, parents' fault, a stay at home, not to have family, can't work, look down at you, not accessible

- Mata tingo (crooked eye)/ta'ea'onga (useless)/ konga e moui (abnormal)/ ne totonu peke ke petie (deserve to have the disability)/ ta'etokanga matua (careless parents)/ ke kehe atu koe meihe family (you're different from your brothers and sisters)

- Papua New Guinea: Disability is caused by witchcraft because of jealousy or to pay back for some wrongs done in the past by the family members of a person with disabilities

- Aia lango aomata aika toamau ibukiia aomata aika a mwauku a rangi n aki kukurei bwa a na iein ibon ivouia mwauku. Ma Iroura ngaira mwauku ao ti bon kona $n$ tabe ma aron ara katei (The people in Kiribati don't want people with a disability to get married because they think people with a disability can't look after themselves)

- They believe that you have a disability because your parents make sins to god (or do many wrong things)

- Tonga: Worshipping idols brings a curse on a person

- Disobedience to church

- If parents do not follow customs, this means that their children will have disability

- Making born child out at night will lead to evil spirits cursing it

- Shark or crocodile worshipping gone wrong will lead to a disability

- A woman drinking an open cut coconut will lead to her having a facial/mouth deformity

- Cooking a chicken whilst breaking its leg will lead to a physical deformity

- Pregnant mothers should not be allowed to walk alone or should not eat certain parts of a pig

- Pointing your finger at a grave

- Taking dead bodies out at night without covering the face will cause a disability from the evil spirits.

- Disabled people cannot marry

- Tuvalu: If you do black magic or use magic in the wrong way it will kick back at you, and if not it will hit your kids

- Papua New Guinea: People believe that you are disabled by angry spirits

- Papua New Guinea: Belief that when someone enters or passes through a sacred site, he or she is disabled

- Papua New Guinea: They look down on people with a disability

- Tagata matimii (disabled persons)

- E le fai aiga (can't marry) 
- E le fanau (can't get birth)

- Matua (parents)

- E ele tatau ona faigaiuega (can't work)

- Disrespect (ignorant of person with disability)

- Disabled person is $\operatorname{mad}^{57}$

\section{The development of charity and medical model thinking}

This inhuman treatment often elicited a charitable or protective response which sometimes led to improvements in the material circumstances of disabled people. Disabled people were objects of charity or asylum and subjected to patronising attitudes based on the non-disabled person's view of them as not fully human or as incapable of living ordinary lives. Motivated by religious thinking, the focus was on supporting basic human needs from a pitying point of view. Disabled people were often put into asylums to protect them from harm and abuse, only to be exposed to more abuse in such institutions.

The Disabled Peoples' Movement has rejected the charity approach in favour of a human rights approach, as under the charity approach disabled people are turned into objects who only receive and do not participate in the processes that shape their lives. The charity model also views impairment as a personal tragedy that can be fixed by the support and rehabilitation the charity provides. Many organisations that started from charitable motives are now allies and supporters of disabled people's rights, although they may not subscribe to the social model because this would mean they have to accept disabled people's analysis of the disabling society.

Charity has not really solved the problems of disabled people. Instead, it has entrenched negative attitudes and made the position of disabled people worse. Disabled people have not benefited from charity, because charity is not part of the socio-economic development process. Disabled people want to be treated as normal citizens with rights. They want to be treated equally and participate as equal citizens in their own communities. To achieve this, political and social action to change society is needed. ${ }^{58}$

As medical science developed it was applied to disabled people with a view to 'curing' them or making them 'normal': disabled people were in the position they were in because of the impairment they had. If the impairment could be fixed, then the disadvantage would disappear. The trouble was, and often still is, that medical science did not know how to get rid of many types of impairments. However, medical knowledge has massively increased in the last 150 years. Improvements in medical science, as long as they can be provided in a low-income environment, can reduce certain types of impairment through rehabilitation or even eradicate them. This is obviously a good thing and should be encouraged

This has led to human beings being healthier and living longer, and to the eradication in richer parts of the world of many conditions which lead to permanent impairment, such as polio, measles and rubella. We know how to prevent many childhood illnesses that kill or lead to permanent impairment, but the knowledge, technology and medicines to do this do not reach those who need them. There are large differences between the rich countries of the North and the developing countries of the South. Eighty per cent of impairment in the South is preventable, e.g. polio, malaria, TB, river blindness, glaucoma, chicken pox and measles, that lead to deafness and blindness. In the North, 80 per cent of impairment is not treatable. 


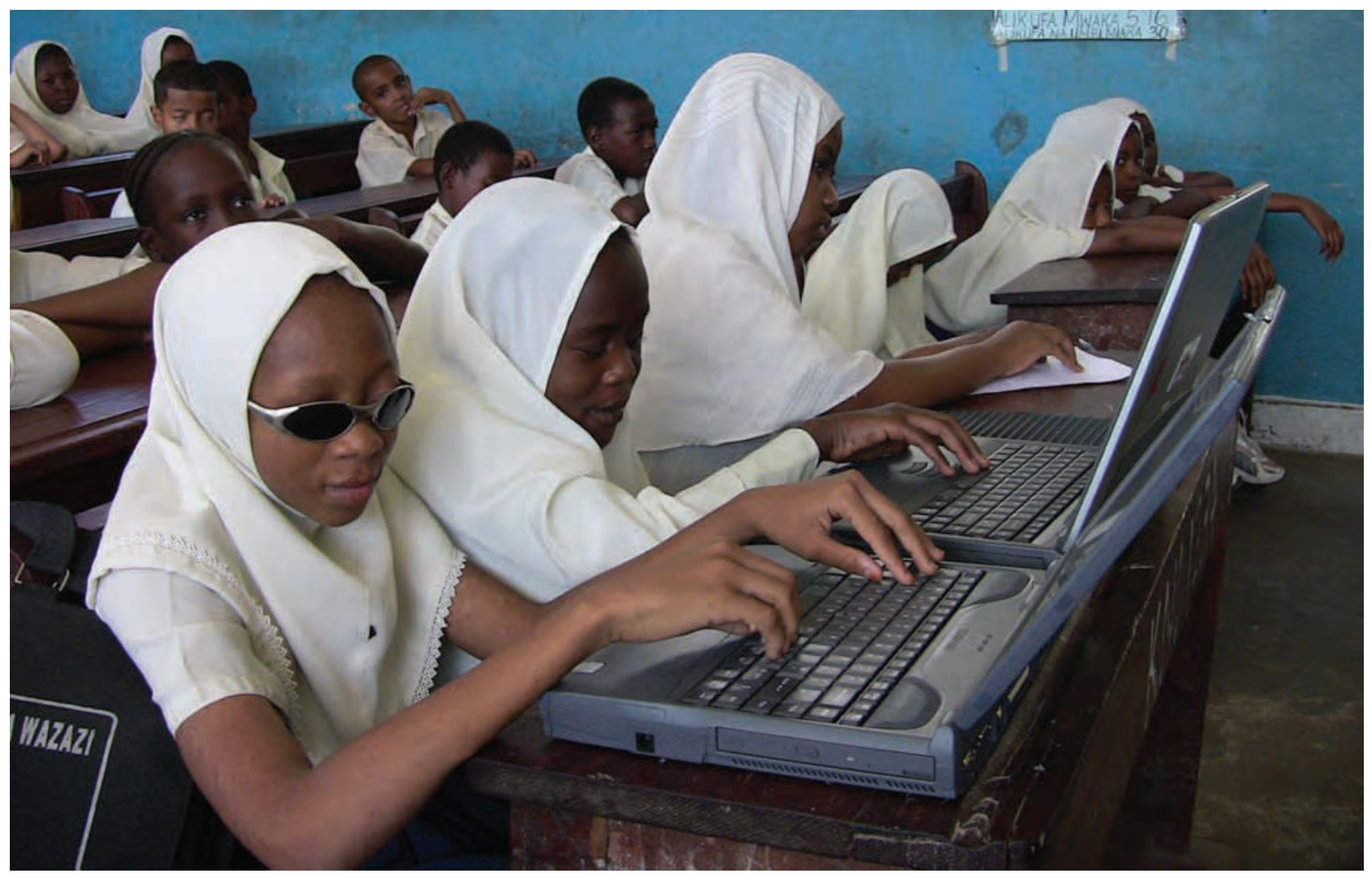

In promoting a social model approach, the disability movement is not counterposing this to the need for access to health services (UNCRPD, Article 25) and habilitation and rehabilitation (Article 26). There should be no discrimination or prejudice in the provision of these services to disabled people. Yet it is often characterised as a polarisation.

The Union of the Physically Impaired Against Segregation (UPIAS), which is often attributed with putting forward the first formulation of the social model of disability, was keen to quash any such argument:

It is of course a fact that we sometimes require skilled medical help to treat our physical impairments - operations, drugs and nursing care. We may also need therapists to help restore or maintain physical function, and to advise us on aids to independence and mobility. But the imposition of medical authority, and of a medical definition of our problems of living in society, have to be resisted strongly. First and foremost we are people, not 'patients', 'cases', 'spastics', 'the deaf', 'the blind', 'wheelchairs' or 'the sick'. Our Union rejects entirely any idea of medical or other experts having the right to tell us how we should live, or withholding information from us, or taking decisions behind our backs.

UPIAS, 1975

This medical model approach focused on the loss of normal function of disabled people and led to them being viewed as negative or in deficit, needing to be made normal. The only trouble was that in the majority of cases this approach did not work. Even where it did work, the disabled person was seen as a collection of symptoms to be treated or subjected to therapy, with their ordinary life put on hold.

What disabled people 'could not do' led to their being categorised by type and degree of impairment and as a result labelled, separated and related to differently from nondisabled people. This attitude often reinforced, and was grafted on to, the persistent traditional views outlined above and so became a potent means of oppression.
Blind and seeing children in class together in Zanzibar. CREDIT: ROY McCONKEY 


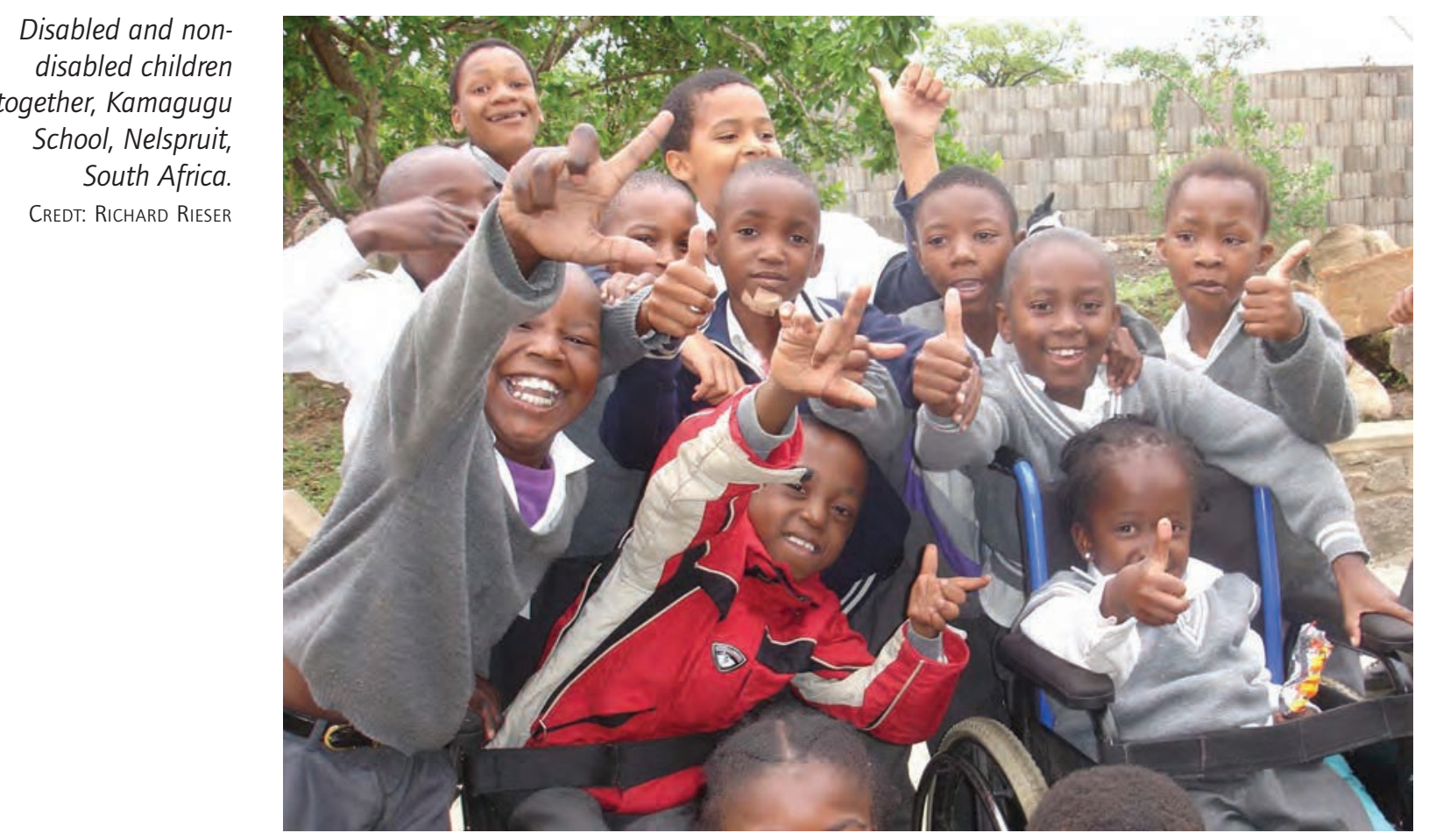

The categorisation by disabled people of medical model thinking as holding them back from winning their full rights does not mean that disabled people do not need interventions from medically trained professionals. Of course they do. A vital part of disabled people's lives and rights is access to medically-based interventions to keep them alive, minimise their impairments and provide the best support available. In much of the South, this knowledge and support is not readily available and is strongly linked to the wealth of the country. When we talk of medical model thinking, we are referring to the way in which disabled people are seen largely or exclusively through a medical lens. Their impairment is focused on, to the exclusion of their entitlement to live in the same way as other members of society.

\section{The development of social model thinking}

Over the last 35 years disabled people themselves began to challenge the consequences of medical model thinking on their lives. The UPIAS was very clear that segregation must be opposed if disabled people were ever to be fully included in society.

The Union's eventual object is to achieve a situation where as physically impaired people we all have the means to choose where and how we wish to live. This will involve the phasing out of segregated institutions maintained by the State or charities. While any of these institutions are maintained at a huge cost, it is inconceivable that we will all receive in addition the full resources needed to provide us with a genuine opportunity to live as we choose.

UPIAS, 1975

The focus has shifted from viewing the problem in the person and their permanent impairment to examining the barriers of attitude, organisation and environment that deny disabled people access to an ordinary life in the culture and society in which they live. In 1981, Disabled Peoples' International adopted the following statement at its world summit: 
Impairment is the loss or limitation of physical, mental or sensory function on a long term or permanent basis.

Disability is the loss or limitation of opportunities to take part in the normal life of the community on an equal level with others due to physical and social barriers.

Disabled Peoples' International, 1981

The difference between the medical and social model perspectives becomes clear in the two diagrammatic explanations shown in Figures 3.1 and 3.2.

The dominant view is the medical model, which shows the problem as the disabled person surrounded by professionals whose main purpose is to make them as 'normal' as possible.

It is important to recognise that medical interventions or support to rehabilitate people's impairments are not dismissed in the social model perspective: instead, they are built upon. The emphasis changes from focusing on the person with impairment, and how to fit them into a society that does not accommodate them, to how to challenge and change the barriers that disable those with impairments.

This perspective both empowers disabled people and provides the basis for a transformative paradigm shift in the way disability is viewed. Box 3.3 illustrates the different approaches that flow from these two perspectives when they are applied to education. The medical model approach leaves schools and society unchanged and disabled people excluded or at a disadvantage. The social model approach allows administrators, teachers and parents to examine their thinking and practice so that they dismantle the barriers and become the allies of disabled students. In this way they can help students to maximise their social and academic achievements, and in the process society will change.

The social model of disability focuses on the barriers and shows the disablement of the person with impairments due to barriers of attitude, environment and organisation.

The social model approach recognises the need to:

- Change people's thinking about disabled people;

- Alter the environment to make it accessible;

- Transform organisations and their policies, practices and procedures;

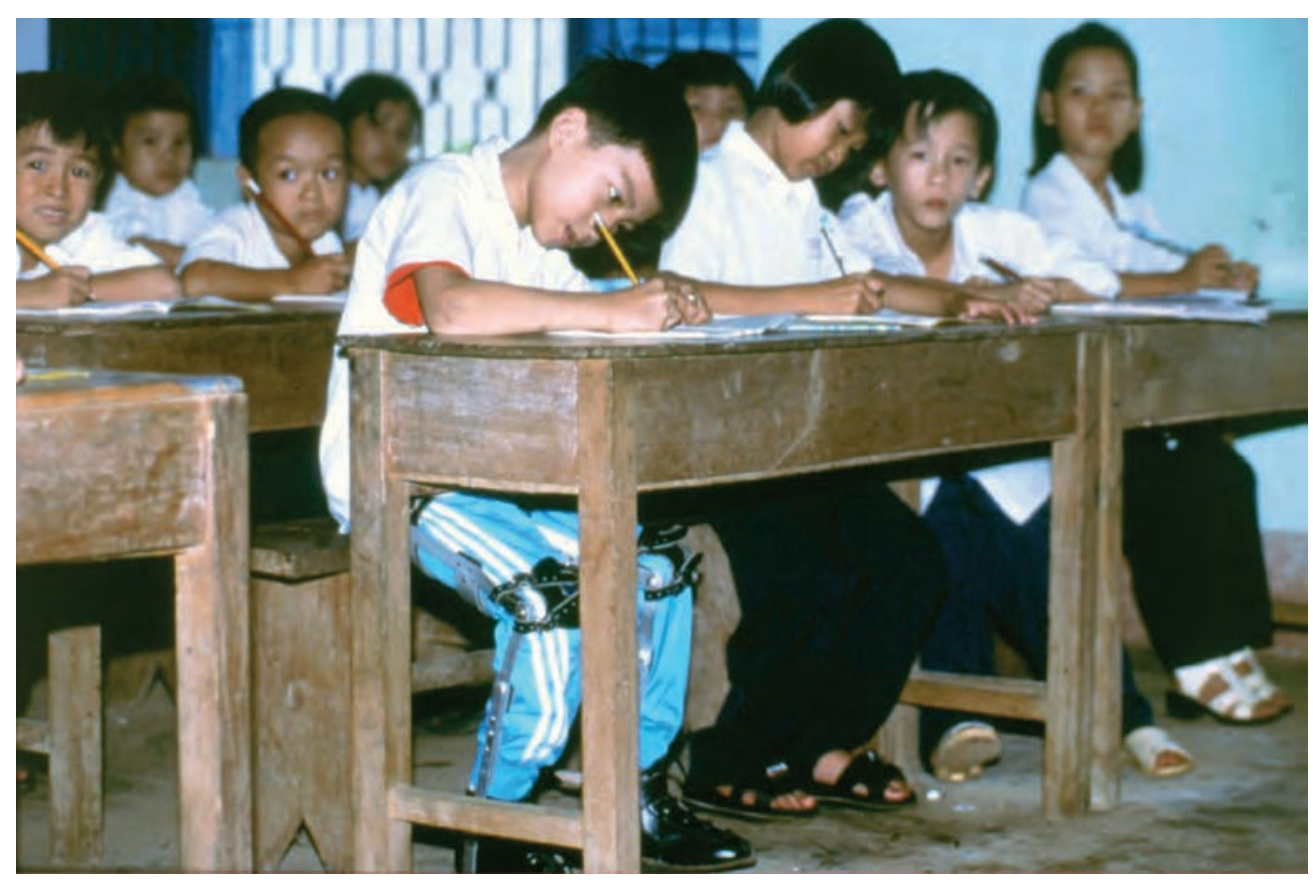

Malaysia: Being together makes sense. CREDIT: UNESCO 


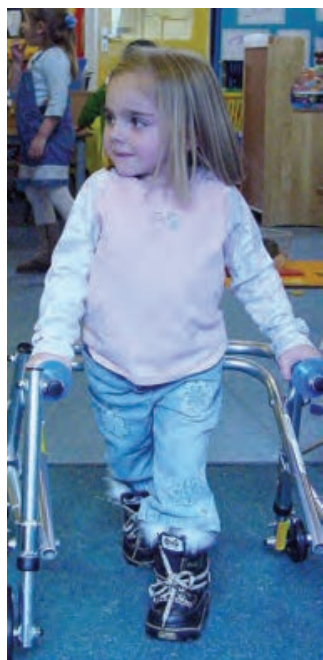

Cameron walking towards a world of rights in the future. CREDIT: RICHARD RIESER
- Urgently counter low self-esteem and poor self-attitude by empowering disabled people to insist upon their rights.

The focus shifts from altering disabled people so that they can fit into a disabling world and society to transforming the society and the world by changing attitudes and removing barriers. This thinking is at the heart of the UN Convention on the Rights of Persons with Disabilities. Its preamble states:

Recognising that disability is an evolving concept and that disability results from the interaction of persons with impairments and attitudinal and environmental barriers that hinders their full and effective participation in society on an equal basis with others.

Looking back, it is interesting to see how far we have come, in that nearly everybody, from the WHO through the World Bank to the UN, now appears to accept this formulation. However, it is quite another thing to apply this analysis effectively. There are now many examples of inclusion projects going wrong for lack of disabled advocates. Inclusion projects need to be led by politically aware disabled people. What does this mean for the development of inclusive education?

Box 3.3 Medical and social model thinking applied to education ${ }^{59}$

\begin{tabular}{|c|c|}
\hline Medical model thinking & Social model thinking \\
\hline Child is faulty & Child is valued \\
\hline Diagnosis & Needs are defined by self and others \\
\hline Labelling & Identify barriers and develop solutions \\
\hline $\begin{array}{l}\text { Impairment becomes focus of } \\
\text { attention }\end{array}$ & Outcome-based programme designed \\
\hline $\begin{array}{l}\text { Assessment, monitoring, therapeutic } \\
\text { programmes imposed }\end{array}$ & $\begin{array}{l}\text { Resources are made available to } \\
\text { ordinary services }\end{array}$ \\
\hline Segregation and alternative services & Training for parents and professionals \\
\hline Ordinary needs put on hold & Relationships nurtured \\
\hline Re-entry if 'normal' enough or & Diversity welcomed, child is included \\
\hline
\end{tabular}
permanent exclusion

Society remains unchanged

Society evolves

Some commentators, such as Coleridge et al. (2010), counterpose the social model with a human rights model, claiming that the social model does not take account of the psychological dimensions of having to come to terms with having an impairment and that disabled people will always needs social protection due to their 'vulnerability'.60 This is to misunderstand the social model. The concept of internalised oppression has been used in relation to the social model to explain the psychological feelings one has of acquiring an impairment when the world is dominated by disabling attitudes (Rieser and Mason, 1990). Disabled people recognise their unequal position in society and require social protection measures to blunt the effects of negative attitudes and behaviour. Both of these areas are consequences of the dominance of medical model thinking.

Coleridge et al. (2010: 31) put forward a human rights model: 
Figure 3.1. The medical model of disability

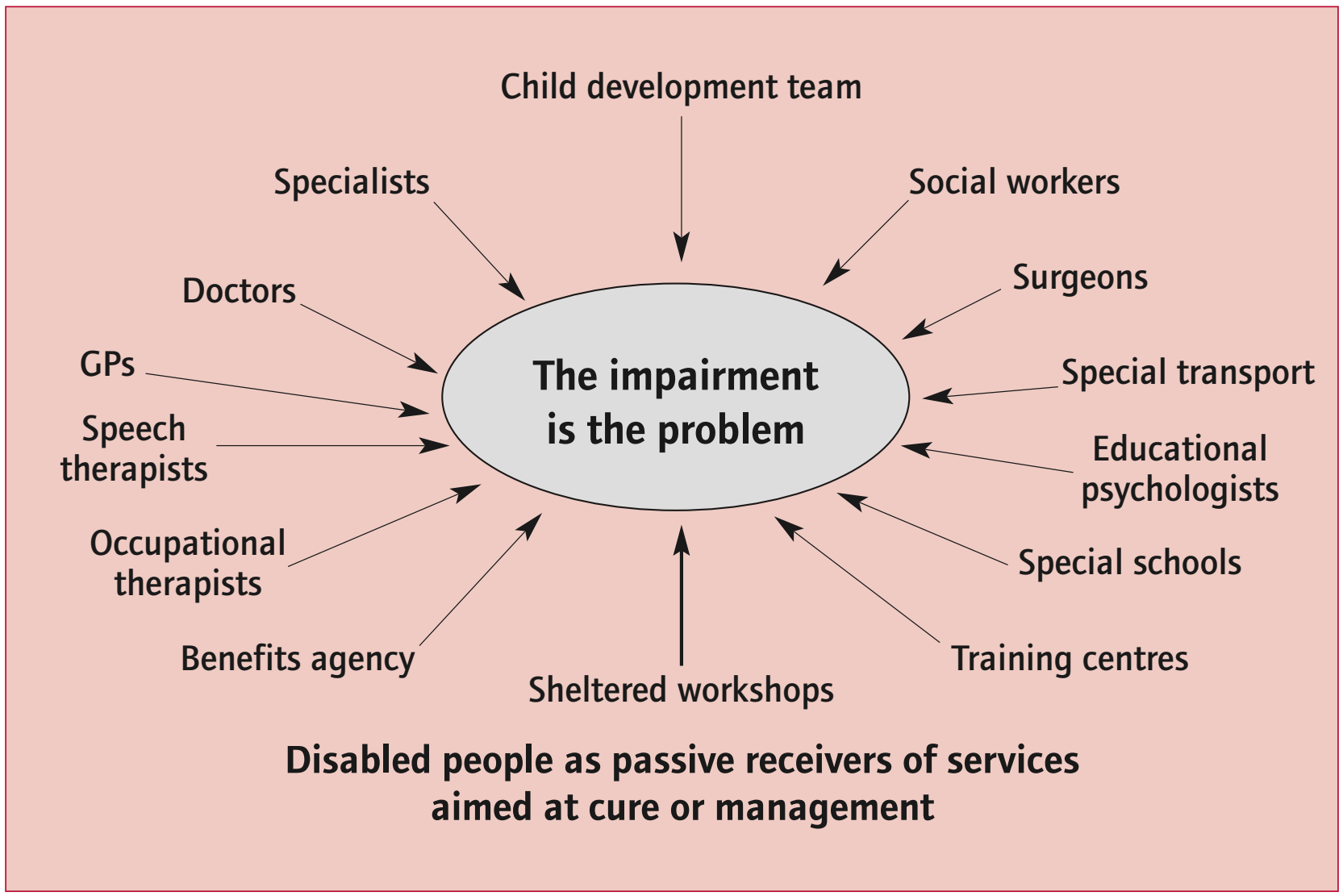

Figure 3.2. The social model of disability

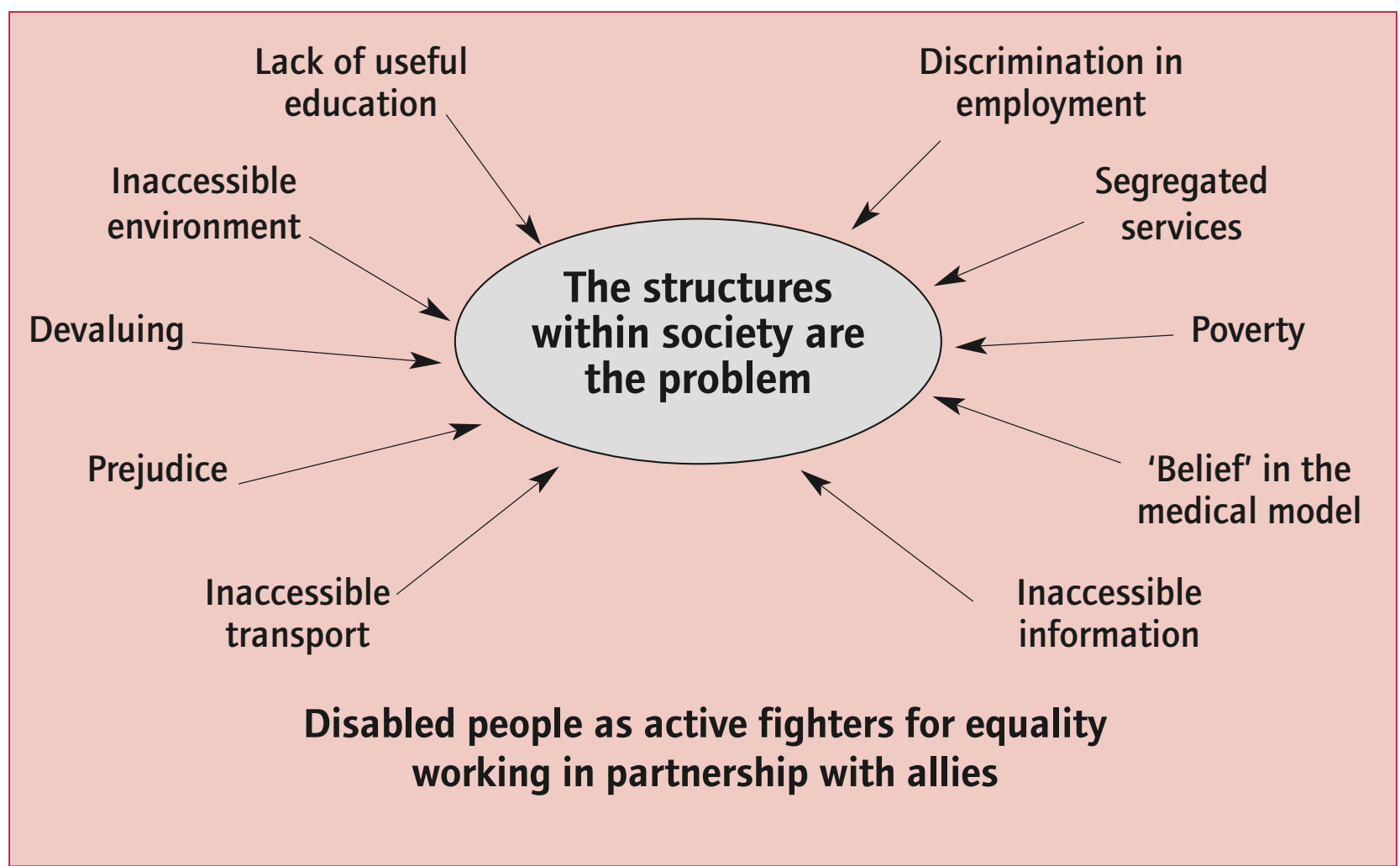




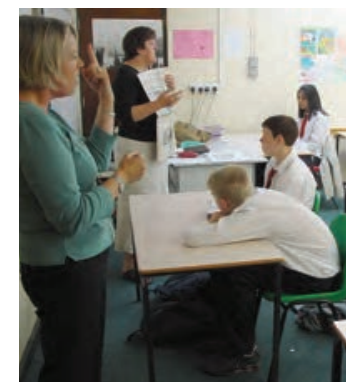

Supporting a deaf pupil in a mainstream secondary school, Stoke Park, Coventry, UK. CREDIT: RICHARD RIESER
The human rights model developed as a result of two main factors: (a) calls by the disability movement for the recognition that disabled people, like non-disabled people, are entitled to the full enjoyment of human rights; and (b) despite the growth in international conventions on human rights in recent decades, the recognition that persons with disabilities were not visible within these treaties. It was these two factors in particular that gave rise to the UNCRPD. In this model empowerment has a much broader definition and scope than in the medical and social models. Participation in decision making, changes to the environment, human rights legislation, control over and access to the skills, knowledge, and support systems that facilitate functional independence, are all vital elements.

But all of these arise from the paradigm shift which is implicit and explicit in the UNCRPD. This is fundamentally the shift from the medical/individual model to the social model of disability. The key to change under the social model is the involvement and empowerment of disabled people and their organisations as the main engines of change.

Coleridge et al. also assert that rehabilitation should be an equal partnership between professionals and disabled people. Given the history, medical model training and power relationships this cannot happen. Disabled people need to control the rehabilitation process. It is dangerous to suggest moving to a human rights model partly to include prevention and rehabilitation when the UNCRPD and the campaigning around it were based on a recognition of the denial of rights due to dominant medical model thinking. The great majority of the world's disability movement subscribes to the need to shift to a social model, which in itself gives rights to disabled people.

Impairment is a universal part of the human condition. The impact varies depending on the economic level of the country and types of impairments vary. There are many reactions to impairment, but they are nearly always negative. This is why the UNCRPD is needed: disablism is rife. The social oppression disabled people face in every country urgently needs tackling throughout all societies. 